Diabetologia (1995) 38: 445-453

\title{
Peptide-based radioimmunoassay for the two isoforms of the human insulin receptor
}

\author{
G. Sesti $^{1}$, R.D'Alfonso ${ }^{1}$, M.D. Vargas Punti ${ }^{1}$, L.Frittitta ${ }^{2}$, V. Trischitta ${ }^{2}$, Y.Y. Liu ${ }^{1}$, P. Borboni ${ }^{1}$, R. Longhi ${ }^{3}$, \\ A. Montemurro ${ }^{1}$, R. Lauro ${ }^{1}$ \\ ${ }^{1}$ Dipartimento di Medicina Interna, Università di Roma - "Tor Vergata", Roma, Italy \\ ${ }^{2}$ Cattedra di Endocrinologia e Patologia Costituzionale, Università di Catania, Catania, Italy \\ ${ }^{3}$ Istituto di Chimica degli Ormoni, Consiglio Nazionale delle Ricerche, Milano, Italy
}

Summary The insulin receptor exists in two isoforms differing by the absence (HIR-A) or presence (HIRB) of 12 amino acids in the COOH-terminus of the $\alpha$-subunit as a consequence of alternative splicing of exon 11. In this study, we developed a radioimmunoassay for the two isoforms employing antibodies raised against two peptides, one (Pep-12) corresponding to residues encoded by exon 11 , and the other (Pep-13) corresponding to a $\mathrm{COOH}$-terminal domain of the $\alpha$-subunit which is common to both HIR-A and HIR-B isoforms. These peptides were iodinated and used as both ligands and standards. The assay is specific, highly reproducible, and sensitive with a detection limit of $10 \mathrm{fmol}$ of receptor. One mole of purified insulin receptor, measured by Scatchard analysis, is read as one mole of receptor in the radioimmunoassay with either Pep-12 or Pep-13 as standards. The radioimmunoassay is applicable to the measurement of total content and relative abundance of the two isoforms in extracts from various tissues. We applied the radioimmunoassay to measure the relative abundance of the two isoforms in fat and muscle from normal, obese non-diabetic and non-insulin-dependent diabetic (NIDDM) subjects. Results demonstrate that expression of the low-affinity HIRB form is significantly increased in obese and NIDDM subjects compared with control subjects. In addition, the increased expression of the HIR-B isoform was significantly correlated with both body mass index $(r=0.52 ; p=0.006)$ and fasting glucose levels $(r=0.59 ; p=0.001)$. [Diabetologia (1995) 38: 445-453]

Key words Insulin receptor isoforms, insulin receptor radioimmunoassay.
The human insulin receptor (HIR) exists in two isoforms which differ by the absence (HIR-A) or presence (HIR-B) of 12 amino acids in the COOH-terminus of the $\alpha$-subunit $[1,2]$. The two isoforms are generated by tissue-specific alternative splicing of the 36-basepair exon 11 [3-5]. There is evidence indicating that the two receptor isoforms are functionally and immunologically different [6-12]. It has been

Received: 8 July 1994 and in revised form: 14 October 1994

Corresponding author: Dr. G. Sesti, Dipartimento di Medicina Interna, Università di Roma - "Tor Vergata", Via Orazio Raimondo, I-00173 Rome, Italy

Abbreviations: HIR, Human insulin receptor; NIDDM, noninsulin-dependent diabetes mellitus; RIA, radioimmunoassay; BSA, bovine serum albumin. shown that the binding affinity for insulin of the HIR-A form is approximately two times higher than that of the HIR-B form $[6,8,10,12]$. This difference in ligand binding is paralleled by a decreased sensitivity for both anabolic and metabolic actions of insulin [9]. Furthermore, the HIR-A form appears to have higher rates of both internalization and recycling [7, 8]. These findings have led to the suggestion that tissue-specific alterations in the relative expression of the two receptor isoforms may play a role in causing insulin resistance, a typical feature of obesity and non-insulin-dependent diabetes mellitus (NIDDM). However, studies on the relative expression of the two mRNA transcripts have led to divergent observations [13-19]. Thus, Mosthaf et al. [13,14] have reported that expression of the two mRNA species is altered in skeletal muscle of both diabetic and non- 
Table 1. Clinical and biochemical data of studied subjects

\begin{tabular}{llll}
\hline & Normal & NIDDM & Obese \\
\hline Number & 16 & 15 & 16 \\
Sex (male/female) & $8 / 8$ & $4 / 11$ & $4 / 12$ \\
Age (year) & $59 \pm 18$ & $59 \pm 14$ & $49 \pm 11$ \\
BMI $\left(\mathrm{kg} / \mathrm{m}^{2}\right)$ & $25 \pm 2$ & $27 \pm 4$ & $31 \pm 2$ \\
Fasting glucose $(\mathrm{mmol} / \mathrm{l})$ & $5.11 \pm 0.66$ & $7.49 \pm 1.38$ & $5.11 \pm 0.88$ \\
$\begin{array}{l}\text { Fasting insulin }(\mu \mathrm{U} / \mathrm{ml}) \\
\begin{array}{l}\text { Duration of diabetes } \\
\text { (years) }\end{array}\end{array}$ & - & $11 \pm 2$ & $13 \pm 7$ \\
\hline
\end{tabular}

diabetic insulin-resistant subjects compared to normal insulin-sensitive control subjects. Also, Norgren et al. [15] found a small, but significant, increase in the expression of the low-affinity HIR-B isoform in skeletal muscle of NIDDM patients. Three other groups were unable to demonstrate any significant difference in the relative abundance of the two mRNA species in skeletal muscle obtained from non-obese normal, obese non-diabetic and NIDDM subjects [16-18]. Discordant results have also been reported when the relative abundance of the two receptor protein isoforms was analysed by immunological assays. Thus, we [19] and others [20] have shown that expression of the two isoforms is altered in isolated adipocytes and in skeletal muscle membranes of NIDDM subjects, respectively. On the contrary, Benecke et al. [16] found no significant difference in the relative abundance of the two receptor protein isoforms in skeletal muscle of normal, obese and NIDDM individuals [16]. In these studies, the relative distribution of the two receptor protein isoforms was measured either by using an isoform-specific autoantiserum that differentially inhibits $\left[{ }^{125} \mathrm{I}\right]$-insulin binding to the two receptor protein isoforms $[19$, 20] or by using an immunoprecipitation assay based on the relative ability of an exon $11+$ specific monoclonal antibody to immunoprecipitate receptors labelled with [ $\left.{ }^{125} I\right]$-insulin [16]. However, because $\left[{ }^{125} \mathrm{I}\right]$-insulin was used as tracer in both immunoassays, accurate quantitation of the relative abundance of the two receptor proteins could be impaired by the difference in insulin binding affinity between HIR-A and HIR-B isoforms [6, 8, 10, 12]. Precise quantification of insulin receptor number in target cells by standard ligand-binding studies is difficult due to the curvilinear nature of Scatchard plots [21]. Radioimmunoassays (RIAs) for the human insulin receptor have been proposed as an alternative method to quantitate the insulin receptor [22-26]. However, these RIAs have used polyclonal or monoclonal antibodies to the insulin receptor that do not discriminate between the two isoforms thus limiting their applications for studying the tissue-specific expression of the two protein receptors.
In the present study, we report the development of a novel peptide-based insulin receptor RIA that is able to precisely quantitate total content of the two receptor protein isoforms and their relative abundance in small samples of human tissues. Using this RIA, we measured the relative abundance of the two isoform proteins in samples of adipose tissue and skeletal muscle from non-obese control subjects, obese non-diabetic, and NIDDM subjects in order to clarify the role of altered expression of the two receptor isoforms in insulin-resistant states.

\section{Subjects and methods}

Preparation of antipeptide antibodies. Antibodies were raised against two synthetic peptides, as previously described [27]. One peptide (Pep-12) corresponds to residues encoded by exon 11, and the other peptide (Pep-13) corresponding to residues 702-719 (numbered according to Ullrich et al. [1]) was derived from a $\mathrm{COOH}$-terminal sequence of the $\alpha$-subunit which is common to both HIR-A and HIR-B isoforms. Antisera (PA12 and PA-13) containing the highest titre were used for the RIA of the insulin receptor. For iodination, a tyrosine residue was added to the $\mathrm{NH}_{2}$-terminal of Pep-12. These peptides were also used as standard in the RIA. Peptides were radioiodinated using the IODOGEN method (Pierce Chemical Co., Rockford, Ill, USA), and monoiodinated peptides were purified by reverse-phase HPLC. The specific activity of ${ }^{125}$ I-labelled peptides was $230-300 \mu \mathrm{Ci} / \mu \mathrm{g}$. Labelled peptides were stable for at least 8 weeks when stored at $4^{\circ} \mathrm{C}$.

Sample preparation. NIH3T3 fibroblast cell line transfected with the HIR-B form and expressing $10^{5}$ binding sites/cell, as determined by Scatchard analysis, was a generous gift from Dr. J. Whittaker (Stonybrook, N. Y., USA) [28]. NIH3T3 fibroblasts transfected with the HIR-A form and expressing $1.5 \times 10^{5}$ binding sites/cell, as estimated by Scatchard analysis, were prepared as previously described [19]. Cells were grown in Dulbecco's modified Eagle's medium supplemented with $10 \%$ (volume/volume) fetal calf serum. Fresh human placentae were obtained from normal subjects after full-term vaginal deliveries. Tissue specimens of liver were obtained from nondiabetic subjects who underwent surgery for uncomplicated gallstone disease. Samples of subcutaneous adipose tissue were obtained from six non-obese normal control subjects, six obese non-diabetic subjects, and five NIDDM patients, whereas specimens of rectus abdominus skeletal muscle were obtained from a separate group of ten non-obese normal control subjects, ten obese non-diabetic, and ten NIDDM subjects during elective abdominal surgery. The subjects were admitted to the hospital for cholecystectomy or total hysterectomy. Clinical and biochemical data of the subjects are shown in Table 1. The control and the obese subjects had normal fasting plasma glucose levels, normal blood pressure, and no family history of diabetes. All diabetic patients were diagnosed according to National Diabetes Data Group criteria [29]. Seven NIDDM patients were treated with diet alone, six with sulfonylurea, and two with insulin. No subject had taken any other medication known to alter insulin or glucose metabolism. Consent was obtained from all subjects after the nature of the procedure was explained. Tissue samples were cleaned of all connective tissue and blood, immediately frozen in liquid nitrogen, and stored at $-70^{\circ} \mathrm{C}$ until use. Isolated adipocytes were prepared by the collagenase digestion method as previously de- 

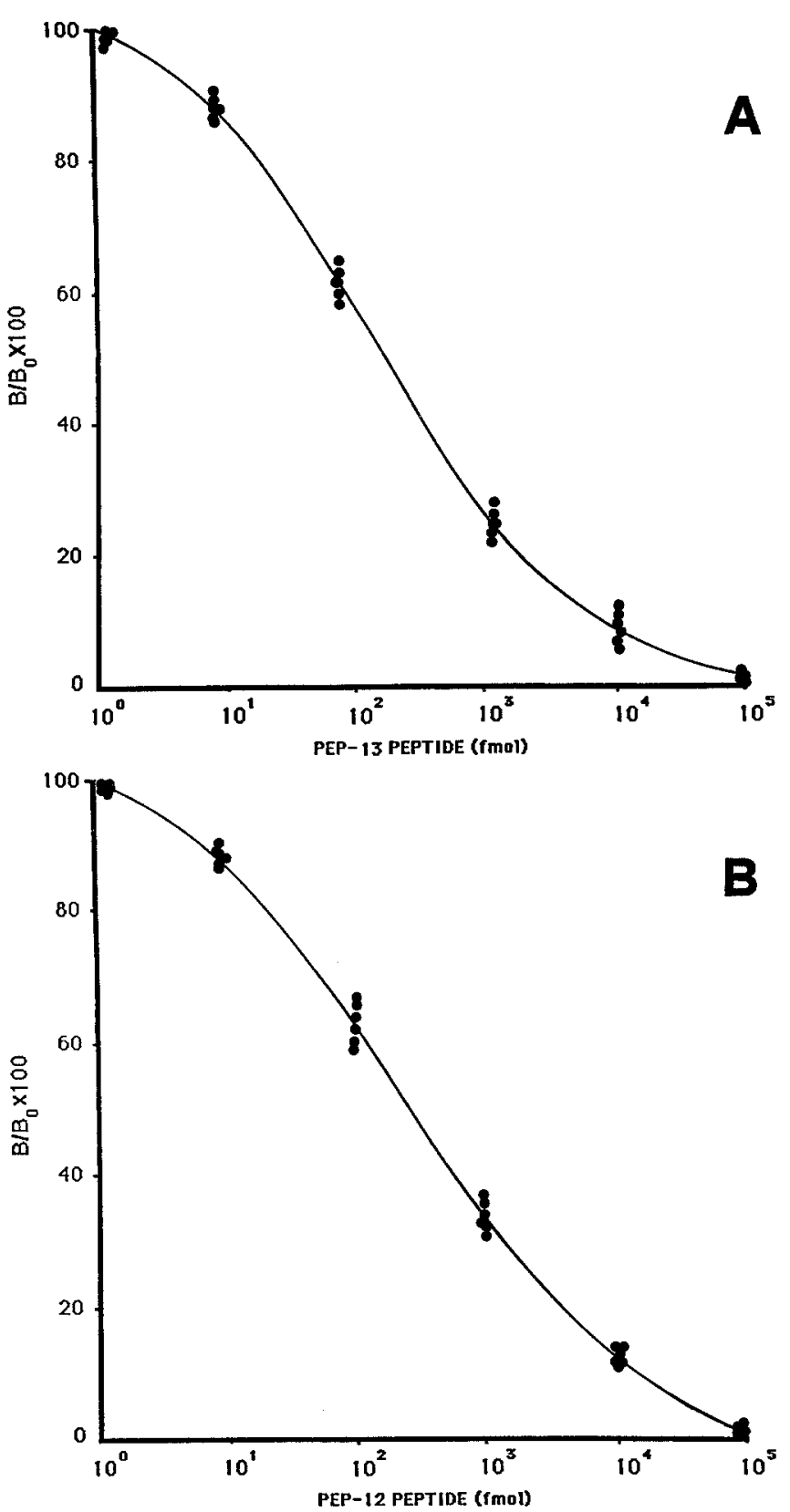

Fig.1. (A, B) Standard curves for Pep-12- and Pep-13-based RIAS. Multiple dilutions of unlabelled Pep-12 or Pep-13 were incubated for $16 \mathrm{~h}$ at $4{ }^{\circ} \mathrm{C}$ with the corresponding antibody (PA-12 or PA-13). ${ }^{125}$ I-peptides at tracer concentration were added, and incubations continued for an additional $24 \mathrm{~h}$ at $4{ }^{\circ} \mathrm{C}$. Goat anti-rabbit immunobeads were then added. After $16 \mathrm{~h}$ at $4^{\circ} \mathrm{C}$, mixtures were centrifuged, pellets were washed and counted. A: standard curve for Pep-13-based RIA. B: standard curve for Pep-12-based RIA. Curves are representative of a single experiment carried out in sextuplicate. Similar results were obtained in five independent experiments

scribed [19]. Extracts from cells or whole tissues were prepared by solubilization in $50 \mathrm{mmol} / 1$ Hepes buffer, $\mathrm{pH} 7.6$, containing $150 \mathrm{mmol} / 1 \mathrm{NaCl}, 1 \%$ Triton $\mathrm{X}-100,1 \mathrm{mg} / \mathrm{ml}$ bacitracin, $2 \mathrm{mmol} / 1$ (PMSF), $1000 \mathrm{units} / \mathrm{ml}$ aprotinin for $60 \mathrm{~min}$ at $4^{\circ} \mathrm{C}$. The lysates were sonicated for $1 \mathrm{~min}$ and insoluble material was removed by centrifugation at $100,000 \times g$ for $60 \mathrm{~min}$ at $4{ }^{\circ} \mathrm{C}$. Soluble fractions were diluted to $0.2 \%$ Triton X-100 and immediately assayed or frozen at $-70^{\circ} \mathrm{C}$ until assayed. Protein content of cell or tissue lysates was determined by the Bradford method [30].

Purification of the insulin receptor. Membranes from normal human placentae were prepared by differential centrifugation as previously described [11]. Placental membranes or confluent NIH3T3 fibroblasts transfected with the HIR-B form were solubilized and insulin receptors were purified to homogeneity by using sequential monoclonal antibody agarose and wheat germ agglutinin-agarose affinity chromatography, as previously described [24]. Protein content of the purified insulin receptor was measured by amino acid composition analysis. Receptor number was determined by Scatchard analysis of insulin binding [21].

Radioimmunoassay. The assay is based on the ability of the two receptor isoforms to compete with radiolabelled sequencespecific peptides for the binding to the corresponding antibody. A secondary antibody was used for separating radiolabelled ligands into antibody-bound and free fractions. For the basic assay, to $9 \times 70-\mathrm{mm}$ glass tubes were added: $200 \mu \mathrm{l}$ of multiple dilutions of test samples, highly purified insulin receptors or unlabelled peptides (Pep-12 or Pep-13) in assay buffer containing $50 \mathrm{mmol} / \mathrm{l}$ Hepes, $150 \mathrm{mmol} / \mathrm{l} \mathrm{NaCl}, 0.1 \%$ Triton $\mathrm{X}-100,1 \mathrm{mmol} / \mathrm{PMSF}, 0.1 \%$ bovine serum albumin (BSA), $\mathrm{pH} 7.6$, and $25 \mu \mathrm{l}$ of anti-peptides antibodies PA-12 or PA-13 (final dilution $1: 5000$ ). Titres of antisera were adjusted to the concentrations at which $30-40 \%$ of the corresponding labelled peptides were bound. After a $16-\mathrm{h}$ incubation at $4^{\circ} \mathrm{C}$, $25 \mu \mathrm{l}$ of ${ }^{125}$ I-peptides $(10,000-15,000 \mathrm{cpm})$ were added, and samples were incubated for an additional $24 \mathrm{~h}$ at $4^{\circ} \mathrm{C}$. Goat anti-rabbit immunobeads (50 $\mu$ ) (Bio-Rad, Richmond, Calif., USA) (final dilution $1: 150$ ) were then added. After $16 \mathrm{~h}$ at $4^{\circ} \mathrm{C}$, mixtures were centrifuged at $3000 \times g$ for $30 \mathrm{~min}$ at $4{ }^{\circ} \mathrm{C}$, supernatants were aspirated, pellets were washed once with assay buffer and bound radioactivity was counted. Experiments were performed in triplicate, and values for test samples were measured in the functional portion of standard curve (15$85 \%$ displacement).

Western blotting. Extracts from whole tissues were subjected to sodium dodecyl sulphate-polyacrylamide gel electrophoresis (SDS-PAGE) under reducing conditions, as previously described [31]. Proteins $(50 \mu \mathrm{g} /$ lane) resolved by SDS-PAGE were electrophoretically transferred to nitrocellulose filters. The non-specific binding sites of membranes were blocked by a 2-h incubation of Tris-buffered saline (TBS, $\mathrm{pH} 7.5$ ) containing $5 \%$ BSA. The filters were then incubated for $16 \mathrm{~h}$ at $4^{\circ} \mathrm{C}$ with affinity-purified PA-12 or PA-13. Thereafter, the filters were washed with TBS, and incubated for $2 \mathrm{~h}$ at room temperature with ${ }^{125}$ I-protein A. After extensive washings with TBS, the filters were dried and exposed to Kodak X-Omat film at $-70^{\circ} \mathrm{C}$. Band densities were quantified by scanning densitometry.

\section{Statistical analysis.}

Unpaired Student's $t$-test was used to compare mean values, and linear regression was used for correlation analysis.

\section{Results}

Validation of the peptide-based RIA. The standard curves of the RIA for Pep-12 and Pep-13 are shown in Figure 1. The binding of labelled peptides 

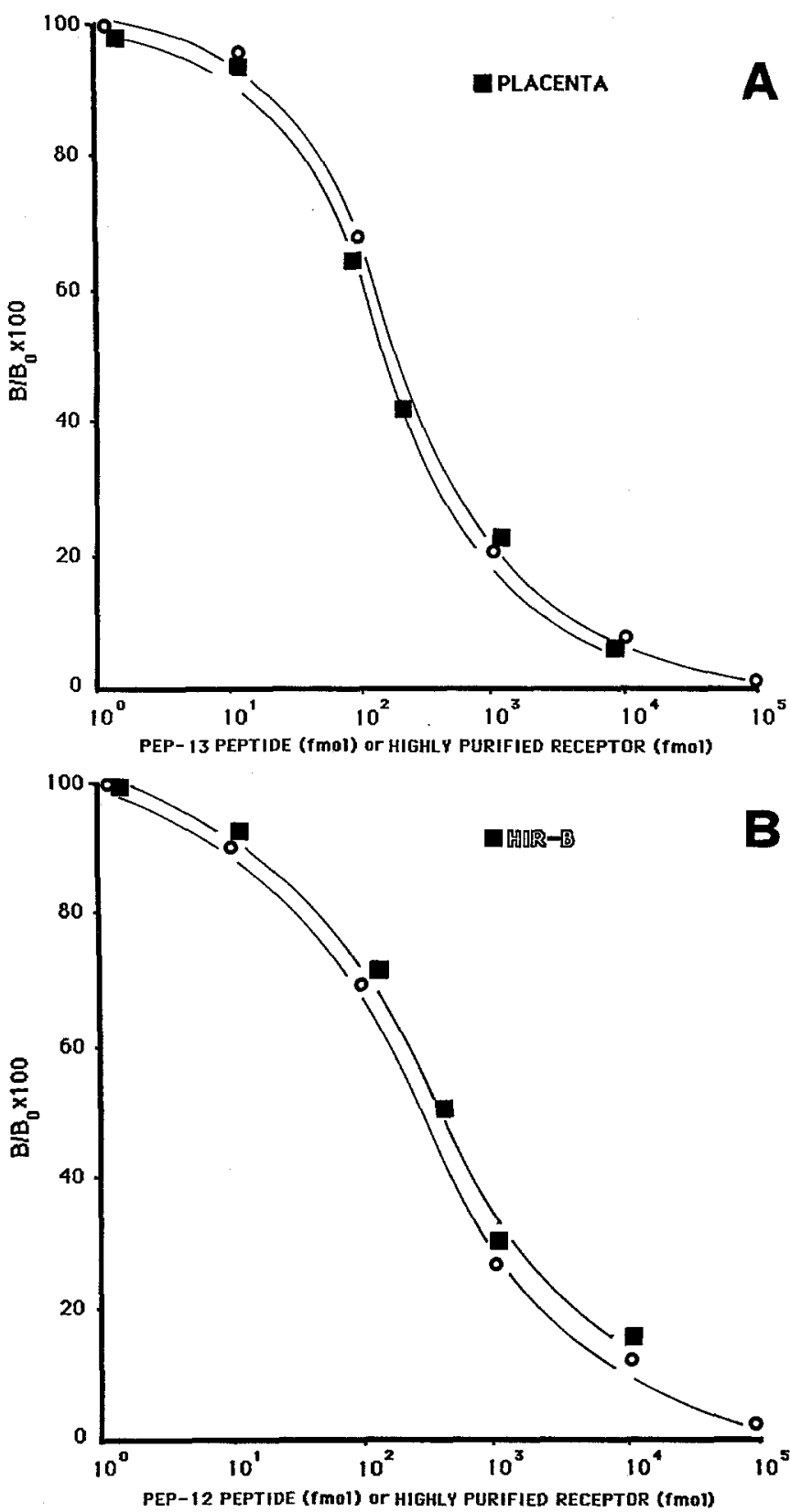

Fig. 2. (A, B) Displacement of labelled peptides by highly purified insulin receptor. Multiple dilutions of highly purified insulin receptors were incubated for $16 \mathrm{~h}$ at $4^{\circ} \mathrm{C}$ with anti-peptides antibodies (PA-12 or PA-13). ${ }^{125}$ I-peptides (Pep-12 or Pep-13) were added, and samples were incubated for an additional $24 \mathrm{~h}$ at $4^{\circ} \mathrm{C}$. Goat anti-rabbit immunobeads were then added. After $16 \mathrm{~h}$ at $4^{\circ} \mathrm{C}$, mixtures were centrifuged, pellets were washed and counted. A: competition curve of highly purified insulin receptor from placenta ( $\mathbf{G})$ for the binding of ${ }^{125} \mathrm{I}-\mathrm{Pep}-13$ to the corresponding antiserum. Standard curve $(0)$. B: competition curve of highly purified receptors from NIH3T3 cells expressing the HIR-B ( $\boldsymbol{\square})$ form for the binding of ${ }^{125} \mathrm{I}$-Pep-12 to the corresponding antiserum. Standard curve (O). Curves are representative of a single experiment carried out in triplicate. Similar results were obtained in three independent experiments
( ${ }^{125} \mathrm{I}-\mathrm{Pep}-12$ or $\left.{ }^{125} \mathrm{I}-\mathrm{Pep}-13\right)$ to the corresponding antibodies was completely inhibited at $10^{-10} \mathrm{~mol} / 0.3 \mathrm{ml}$. For both peptides, a detectable inhibition of binding was seen at $10^{-14} \mathrm{~mol} / 0.3 \mathrm{ml}$, whereas half-maximal displacement was observed at $2 \times 10^{-13} \mathrm{~mol} / 0.3 \mathrm{ml}$ (Fig.1). Both the assay with PA-12 and the assay with PA-13 were highly reproducible with respect to both intra-and inter-assay variations. The intra-assay coefficient of variation in the functional portion of the standard curve (85-15\% displacement) was $4.5 \%$ for Pep-12 and $3.8 \%$ for Pep-13, respectively. Standard curves were performed with $10^{-15}, 10^{-14}$, $10^{-13}, 10^{-12}, 10^{-11}, 10^{-10} \mathrm{~mol} / 0.3 \mathrm{ml}$ of unlabelled Pep-12 or Pep 13. In ten experiments the inter-assay coefficients of variation for these concentrations were $3.1,4.5,10.1,12.2,12.0$ and $10.4 \%$ for Pep-12 and $2.8,5.9,7.0,12.1,12.5$ and $11.8 \%$ for Pep-13, respectively. Next, we studied whether the HIR could compete with ${ }^{125}$ I-Pep-12 or ${ }^{125}$ I-Pep-13 for the binding to the corresponding antibody in this assay system. The displacement curve produced by highly purified receptors from placenta which is known to contain both the HIR-A and the HIR-B form was parallel to the Pep-13 standard (Fig. 2a). Similarly, highly purified receptors from transfected cells expressing the HIR-B form produced competition curves that were parallel to the Pep-12 standard (Fig. 2b). The concentrations of highly purified receptors from either placenta or transfected cells expressing the HIR-B isoform were determined by Scatchard analysis of insulin binding. A good correlation was observed between the moles of purified receptor calculated by Scatchard plots and the molar equivalents to peptides measured in peptide-based RIAs. A representative preparation of purified receptor from placenta had $2.9 \mathrm{nmol} / 1$ receptor, as measured by Scatchard analysis of insulin binding, and $2.2 \mathrm{nmol} / \mathrm{l} \mathrm{re}-$ ceptor when determined with the Pep-13-based RIA. A preparation of purified receptor from cells transfected with the HIR-B isoform contained $2.3 \mathrm{nmol} / 1 \mathrm{receptor}$, as measured by Scatchard analysis, and $1.9 \mathrm{nmol} / 1$ receptor as determined by the Pep-12-based RIA.

Specificity of peptide-based RIA. The specificity of both Pep-12- and Pep-13-based RIA was investigated by using NIH3T3 cells transfected with and expressing either the HIR-A form or the HIR-B form. Cell lysates from both sources competed with ${ }^{125} \mathrm{I}$ Pep-13 for the corresponding antiserum, and competition-inhibition curves were parallel to the peptide standard (Fig. 3 a). In contrast, only cellular extract from NIH3T3 transfectants expressing the HIR-B isoform was able to compete with ${ }^{125}$ I-Pep-12 for the corresponding antiserum and its competition-inhibition curve was parallel to the peptide standard (Fig. 3b). The antibody directed against the Pep-13 does not react with homologous peptides of the insu- 

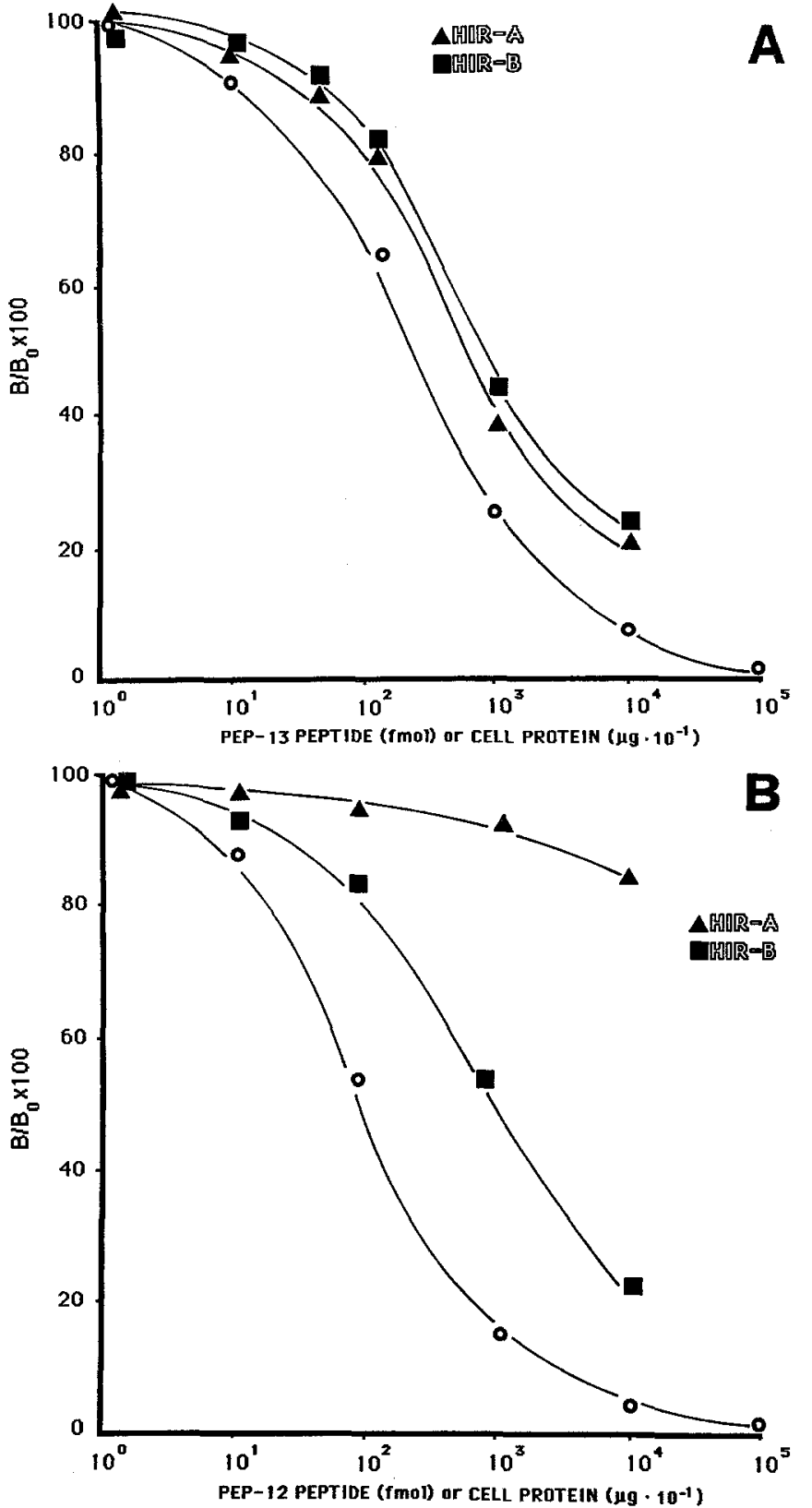

Fig. 3. (A, B) Specificity of RIA for the two isoforms of the insulin receptor. A: competition curve of solubilized extracts from NIH3T3 cells expressing either the HIR-A form $(\boldsymbol{\Delta})$ or the HIR-B form ( $\boldsymbol{m}$ ) for the binding of ${ }^{125} \mathrm{I}-\mathrm{Pep}-13$ to the corresponding antiserum. Standard curve (O). B: competition curve of solubilized extracts from NIH3T3 cells expressing either the HIR-A form ( $\boldsymbol{\Delta}$ ) or the HIR-B form ( $\boldsymbol{v}$ ) for the binding of ${ }^{125}$ I-Pep-12 to the corresponding antiserum. Standard curve $(O)$. Curves are representative of a single experiment carried out in triplicate. Similar results were obtained in three independent experiments

lin-like growth factor I (IGF-I) receptor $\alpha$-subunit (data not shown). The number of receptors measured by both peptide-based RIAs was unaltered by incubation of cell lysates in the presence or absence of $1 \mu \mathrm{mol} / \mathrm{h}$ insulin for $4 \mathrm{~h}$ at $4^{\circ} \mathrm{C}$ before addition of the corresponding antibody. Therefore, Pep-13- based RIA can effectively and specifically measure the total amount of HIR (HIR-A plus HIR-B) in tissues, whereas Pep-12-based RIA only measures the amount of HIR-B isoform.

Quantitation of relative abundance of the two receptor isoforms in human tissues. Using this dual peptidebased RIA we attempted to measure both the absolute content and the relative abundance of the two receptor isoforms in various human tissues. Tissue extracts were prepared from liver, placenta, adipose tissue, and skeletal muscle, and tested for their ability to compete with either ${ }^{125}$ I-Pep-12 or ${ }^{125}$ I-Pep-13 for the corresponding antibody in the RIA. Displacement curves produced by multiple dilutions of tissue extracts were parallel to standard curves produced by both Pep-12 and Pep-13 (data not shown). Total HIR and HIR-B form amounts in tissue extracts expressed as $\mathrm{pmol}$ receptor/mg protein are shown in Table 2. Placenta and liver have higher concentrations of HIR compared with adipose tissue and skeletal muscle. From these data, the ratio of the two receptor species was determined, and the relative abundance of the two isoforms was expressed as the percentage of HIR-B form measured by Pep-12-based RIA vs total insulin receptor content measured by Pep-13-based RIA. As shown in Table 2, results obtained reveal that in placenta, skeletal muscle, and adipose tissue the two receptor protein isoforms are equally expressed, whereas in the liver the HIR-B isoform is predominant. To further validate the present RIA, the relative abundance of the two receptor protein isoforms was determined using a quantitative Western blotting analysis. A representative Western blotting analysis of tissue extracts is shown in Figure 4 in which both PA-12 and PA-13 detect a protein of $\sim 130,000 \mathrm{Da}$. The intensities of the bands were quantified by scanning densitometry and expressed as arbitrary units. The ratio of band intensities obtained with the two antibodies in four experiments was calculated, and the relative abundance of the two receptor isoforms was expressed as the percentage \pm SD of the HIR-B isoform vs the total HIR content. Liver contains predominantly the HIR-B form $(87 \pm 4 \%)$, whereas placenta, skeletal muscle, and adipose tissue contain both isoforms in nearly equal amounts (HIR-B/total HIR $=53 \pm 3,54 \pm 6$, and $55 \pm 5 \%$, respectively). These results were in close agreement with the pattern of tissue-specific protein isoform expression obtained with the present RIA.

Quantitation of relative abundance of the two receptor isoforms in adipose tissue and skeletal muscle from control, obese non-diabetic and NIDDM subjects. We employed this dual peptide-based RIA to measure the relative abundance of the two receptor isoforms in samples of adipose tissue and skeletal muscle 
Table 2. Total content and relative abundance of the two receptor isoforms in human tissues obtained from competition curves of tissue extracts for the binding of ${ }^{125} \mathrm{I}-\mathrm{Pep}-12$ or ${ }^{125} \mathrm{I}$ Pep-13 to the corresponding antiserum

\begin{tabular}{llll}
\hline Tissue & $\begin{array}{l}\text { Total HIR } \\
\text { pmol/mg protein }\end{array}$ & $\begin{array}{l}\text { HIR-B } \\
\text { pmol/mg protein }\end{array}$ & $\begin{array}{l}\text { HIR-B/Total } \\
\text { HIR (\%) }\end{array}$ \\
\hline Placenta & $3.9 \pm 1$ & $2.0 \pm 0.6$ & 51 \\
Liver & $3.5 \pm 1.2$ & $3.1 \pm 1.2$ & 88 \\
Muscle & $2.2 \pm 0.5$ & $1.1 \pm 0.4$ & 50 \\
Fat & $2.7 \pm 0.9$ & $1.4 \pm 0.5$ & 52 \\
\hline
\end{tabular}

Values are means \pm SD of five experiments in triplicate

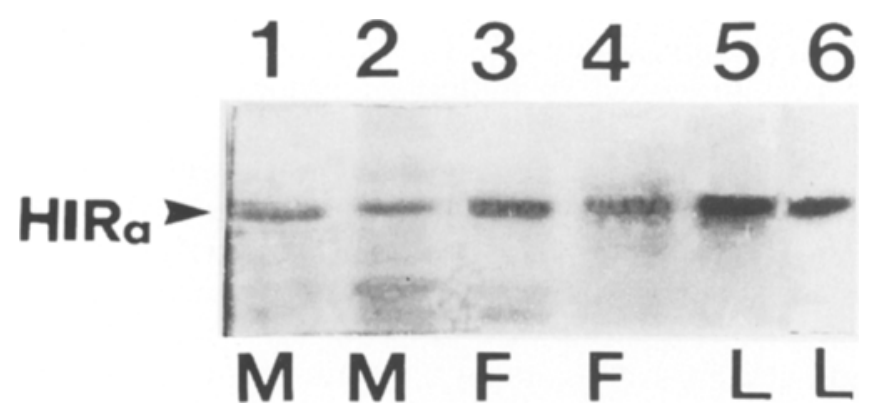

Fig. 4. Quantitation of the relative abundance of the two receptor protein isoforms in various human tissues by Western blotting analysis. Representative Western blotting analysis of skeletal muscle (M), fat (F), and liver (L). Tissue extracts $(50 \mu \mathrm{g} /$ lane) were separated by reducing SDS-polyacrylamide gel electrophoresis and transferred to nitrocellulose filters. The filters were blotted with affinity purified PA-12 (lanes $2,4,6$ ) or PA-13 (lanes $1,3,5$ ) followed by ${ }^{125}$ I-protein A, and autoradiographed. The intensities of the bands were determined by scanning densitometry. With PA-12, the relative intensities expressed as arbitrary densitometric units were: $1.62(\mathrm{M}), 3.01$ $(F)$, and $5.80(\mathrm{~L})$. With PA-13, the relative intensities expressed as arbitrary densitometric units were: $3.11(\mathrm{M}), 5.08$ $(\mathrm{F})$, and $6.51(\mathrm{~L})$. Arrowhead shows the $\alpha$-subunits of the two receptor isoforms

from non-obese normal control subjects, obese nondiabetic, and NIDDM subjects. Preliminary experiments conducted using tissue extracts from either whole adipose tissue specimens or isolated adipocytes of three normal subjects revealed that the measurements of the relative abundance of the two receptor isoforms did not differ between the tissue preparations (the mean percentage of HIR-B vs total HIR was $52 \pm 6$ and $49 \pm 5 \%$, respectively, for whole adipose tissue and isolated adipocytes). Therefore, subsequent experiments were performed using extracts prepared from whole tissue specimens. Samples were assayed simultaneously, and three separate assays were performed in triplicate. The relative abundance of the two receptor protein isoforms was expressed as the percentage of HIR-B isoform content vs total receptor content. Mean values for each subject are shown in Figure 5. The percentage of HIR-B isoform was significantly higher in adipose tissue from six obese non-diabetic $(74 \pm 10 \%, p=0.01)$

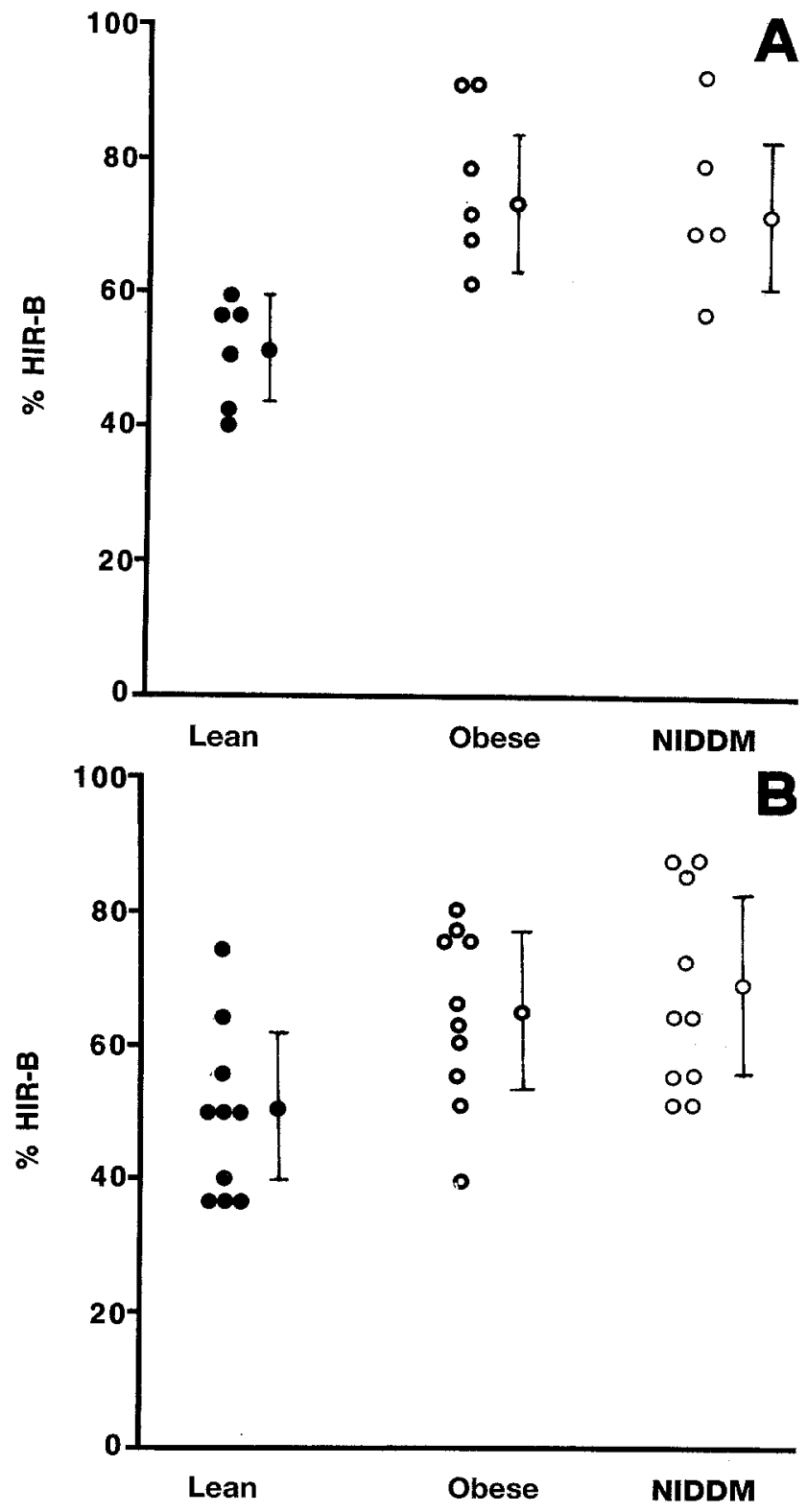

Fig.5. (A, B) Relative abundance of the HIR-B isoform in adipose tissue $(A)$ and in skeletal muscle $(B)$ from lean normal control, obese non-diabetic, and NIDDM subjects. Tissue extracts were prepared from each adipose $(\mathbf{A})$ or muscle sample (B) and assayed simultaneously in triplicate. The relative abundance of the two receptor protein isoforms is expressed as the percentage of HIR-B form vs total receptor content which is derived from the ratio of the two receptor species determined by radioimmunoassy. Each point represents the mean value for a single subject measured in three assays. The mean \pm SD for each group of subjects is shown beside the individual distribution

and five NIDDM subjects $(69 \pm 11 \%, p=0.03)$ compared with six non-obese normal subjects $(51 \pm 7 \%)$ (Fig. 5a). In skeletal muscle the mean percentage of HIR-B isoform was significantly higher in ten obese non-diabetic $(63 \pm 11 \%, p=0.02)$ and 10 NIDDM subjects $(66 \pm 13 \%, p=0.02)$ compared with 10 nonobese normal control subjects $(50 \pm 10 \%)$ (Fig. 5 b). 

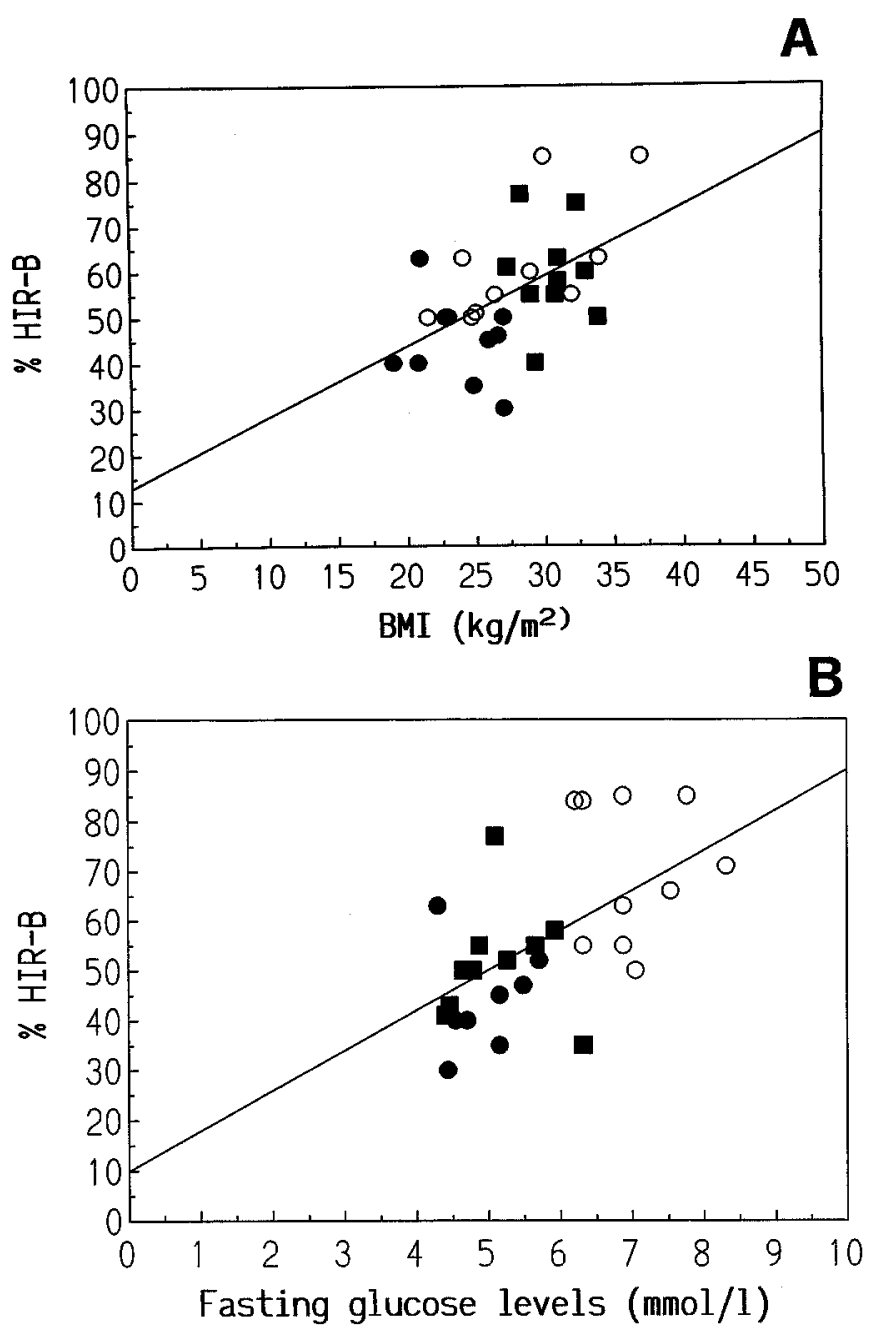

Fig. 6. (A, B) Relative abundance of the HIR-B isoform in skeletal muscle in relation to $B M I(A)$ and fasting glucose levels $(B)$. A: relative abundance of the two receptor isoforms expressed as the percentage of HIR-B form vs BMI $\left(\mathrm{kg} / \mathrm{m}^{2}\right)$. B: relative abundance of the two receptor isoforms expressed as the percentage of HIR-B form vs fasting glucose levels $(\mathrm{mmol} / \mathrm{l})$. Normal control subjects $(\bullet)$, obese non-diabetic (ם), and NIDDM subjects (O)

Among these 30 study participants, an increased expression of the HIR-B isoform was significantly correlated with body mass index (BMI) (Fig. 6a; $r=0.52 ; p=0.006)$ as well as with fasting glucose levels (Fig. 6b; $r=0.59 ; p=0.001$ ). A small, but not significant, correlation was found between insulin receptor isoform expression and fasting insulin levels $(r=0.34 ; p=0.07 ; n=18)$.

\section{Discussion}

In the present study, we have developed and applied a novel dual peptide-based RIA specific for the two isoforms of the human insulin receptor. Two antisera were used in the RIA, one (PA-12) directed against the amino acid sequence encoded by exon 11 , and the other (PA-13) directed against a carboxy-terminal sequence of the $\alpha$-subunit which is common to HIR-A and -B variants. Employing these two antisera and the corresponding labelled peptides, we were able to precisely quantitate total content and relative abundance of the two isoforms of the insulin receptor in small samples of human tissues. Both Pep-12and Pep-13-based RIAs are specific, highly reproducible, and sensitive with a detection limit of $10 \mathrm{fmol}$ of receptor. This sensitivity allows the quantification of the two isoforms of the insulin receptor in tissue samples as small as $50-100 \mu \mathrm{g}$ of liver, placenta, fat or muscle. Using preparations of highly purified receptor, we found a good correlation between the moles of receptor determined by Scatchard analysis of insulin binding and the molar equivalents to Pep-12 or Pep-13 measured in the RIA, thus indicating that insulin receptor and peptide ligand are seen as equimolar in the RIA. This peptide-based RIA, like other previously reported RIAs [22-26], offers several advantages over standard ligand-binding assays. Precise quantitation of the two receptor isoforms does not require Scatchard analysis which may be difficult to perform due to the curvilinear nature of the binding plot [21]. Small tissue specimens are needed for the assay, and tissues can be stored until analysis. The assay can be used for simultaneous measurements of the two receptor protein isoforms in multiple samples without further purification of the extracted receptors. The use of stable peptides as radioactive ligands eliminates the need for highly purified preparations of the insulin receptor for use as standard. In addition, the present RIA measures the number of the two receptor isoforms present in tissue samples independently of their binding properties. Several lines of evidence argue against the possibility that the IGF-I receptor interferes with this dual peptide-based RIA. Firstly, the IGF-I receptor lacks the homologous sequence encoded by exon 11 of the insulin receptor gene [32]. Secondly, the antibody directed against the Pep-13 does not react with peptides corresponding to the homologous sequence of the carboxy-terminal region of the IGF-I receptor $\alpha$-subunit. Additionally, both PA-12 and PA-13 antibodies react exclusively with the corresponding insulin receptor isoforms of hybrid insulin/IGF-I receptors as estimated by their relative capability to immunoprecipitate only a fraction of total precipitable placental receptors labelled with $\left[{ }^{125} \mathrm{I}\right]$-IGF-I (unpublished data).

We have applied this assay to precisely quantitate the relative abundance of the two human insulin receptor protein isoforms in various human tissues. Results obtained show that placenta, skeletal muscle and adipose tissue contain both HIR-A and HIR-B isoform in nearly equal amounts whereas liver contains predominantly the HIR-B isoform. This pattern of tissue-specific expression of the two receptor protein isoforms correlates well with the previously 
reported pattern of expression of the two mRNA species $[4-6,32]$. Furthermore, our data are generally in agreement with those of previous studies in which the relative abundance of the two receptor proteins was measured by other immunological assays $[11,16$, 19, 20, 33]. However, in all tissues tested, we found a slightly higher mean percentage of the HIR-B receptor protein than those observed in previous studies $[11,16,19,20,33]$. This disparity may be due to methodological differences between the present RIA which quantitates the two receptor species independently of their binding properties and previous immunoassays in which ${ }^{125}$ I-insulin was used as ligand. Since the two receptor isoforms have different affinities for insulin (HIR-A > HIR-B), it is possible that previous studies have underestimated the actual abundance of the low-affinity HIR-B isoform. We found that in liver the HIR-B form is predominant, but the absolute number of insulin receptors is higher than in other insulin target tissues such as muscle and fat. It is tempting to speculate that the predominance of the low-affinity HIR-B isoform in liver might contribute to compensate for the higher portal insulin concentrations to which the liver is exposed in vivo, whereas the high number of insulin receptors would allow the liver to respond with relatively high sensitivity to physiological changes in pancreatic hormone secretion in terms of insulin hepatic bioeffects.

It has been speculated that alteration in the relative expression of the two insulin receptor isoforms may contribute to in vivo insulin resistance; data collected on this are at present controversial [13-20]. It has been reported by some [13-15], but not all authors [16-18], that both diabetic and non-diabetic insulin resistant subjects are characterized by an increased expression of the HIR-B mRNA in skeletal muscle compared with normal insulin sensitive individuals. However, a few studies have addressed the question of whether the relative abundance of the two receptor isoforms is altered in major target tissues of insulin action from obese and NIDDM subjects when assessed at the protein level $[16,19,20]$. In an attempt to resolve some of these controversies, we have applied the present RIA to measure the relative abundance of the two receptor protein isoforms in adipose tissue and skeletal muscle from non-obese normal control subjects, obese non-diabetic and NIDDM subjects. Results obtained in both tissues demonstrate that expression of the low-affinity HIR-B form is significantly increased in obese and NIDDM subjects compared with normal control subjects. These findings are in agreement with those of two previous studies of isolated adipocytes [19] and skeletal muscle membranes [20] obtained from a separate group of NIDDM and control subjects in which the relative abundance of the two receptor proteins on the plasma surface was determined by a different immunological assay. In contrast, Benecke et al. [16] us- ing an immunoprecipitation assay failed to show significant difference in the relative proportion of the two receptor protein isoforms in the skeletal muscle of normal control subjects, obese non-diabetic, and obese NIDDM subjects, although a slightly higher mean percentage of the HIR-B receptor protein was observed in obese and NIDDM subjects compared with normal control subjects. The lack of statistical significance in the relative abundance of the two receptor isoforms observed by Benecke et al. [16] might be due to the smaller number of subjects examined compared to that analysed in the present study. Nevertheless, it has not been ruled out that this discrepancy may be explained by methodological differences in the immunoassays used, contaminations of muscle specimens by connective tissue and blood, differences in clinical characteristics between the subjects examined. Interestingly, we found a significant correlation between high glucose levels and increased expression of the low-affinity HIR-B isoform in skeletal muscle. A tendency toward a correlation between high fasting insulin levels and increased expression of the HIR-B form was also observed. These findings are consistent with previous studies showing that hormonal and metabolic factors regulate both in vivo [34] and in vitro [35-37] the alternative splicing of the insulin receptor mRNA. Together, these observations raise the possibility that regulatory factors such as insulin or glucose levels might affect the expression of the two insulin receptor isoforms in different stages of NIDDM. Although, the in vivo consequences of altered expression of the two insulin receptor isoforms are at present unclear, the present RIA may provide a new tool to monitor the metabolic control of insulin-resistant subjects.

In conclusion, this study demonstrates the feasibility of using the present dual peptide-based radioimmunoassay to precisely quantitate the two insulin receptor isoforms in human tissues and its applicability for studying changes in the relative abundance of the two receptor species in different metabolic states.

Acknowledgements. This work was supported by grants from Ministero dell'Università e della Ricerca Scientifica e Tecnologica, and Istituto per lo Sviluppo delle Scienze Biomediche. M.D. Vargas Punti and Y.-Y.Liu are recipients of a fellowship from the Istituto per lo Sviluppo delle Scienze Biomediche.

\section{References}

1. Ullrich A, Bell JR, Chen EY et al. (1985) Human insulin receptor and its relationship to the tyrosine kinase family of oncogenes. Nature (Lond) 313: 756-761

2. Ebina Y, Ellis L, Jarnagin K et al. (1985) The structural basis for hormone-activated transmembrane signalling. Cell 40: $747-758$

3. Seino S, Seino M, Nishi S, Bell GI (1989) Structure of the human insulin receptor gene and characterization of its promoter. Proc Natl Acad Sci USA 86: 114-118 
4. Seino S, Bell GI (1989) Alternative splicing of human insulin receptor messenger RNA. Biochem Biophys Res Comm 159: 312-316

5. Moller DE, Yokota A, Caro JF, Flier JE (1989) Tissue-specific expression of two alternative spliced insulin receptor mRNA in man. Mol Endocrinol 3: 1263-1269

6. Mosthaf L, Grako D, Dull TJ, Coussens L, Ullrich A, McClain DA (1990) Functionally distinct insulin receptors generated by tissue-specific alternative splicing. EMBO J 9: 2409-2413

7. Vogt B, Carrascosa JM, Ermel B, Ullrich A, Häring HU (1991) The two isotypes of the human insulin receptor (HIR-A and HIR-B) follow different internalization kinetics. Biochem Biophys Res Comm 177: 1013-1018

8. Yamaguchi Y, Flier JS, Yokota A, Benecke H, Backer JM, Moller DE (1991) Functional properties of two naturally occurring isoforms of the human insulin receptor in Chinese hamster ovary cells. Endocrinology 129: 2058-2066

9. McClain DA (1991) Different ligand affinities of the two human insulin receptor splice variants are reflected in parallel changes in sensitivity for insulin action. Mol Endocrinol 5: 734-739

10. Kellerer M, Lammers R, Ermel B et al. (1992) Distinct $\alpha$ subunit structures of human insulin receptor $\mathrm{A}$ and $\mathrm{B}$ variants determine differences in tyrosine kinase activities. Biochemistry 31: 4588-4596

11. Sesti G, Marini MA, Montemurro A et al. (1992) Evidence that two naturally occurring human insulin receptor $\alpha$-subunit variants are immunologically distinct. Diabetes 41: 611

12. Yamaguchi Y, Flier JS, Benecke $H$, Ransil BJ, Moller DE (1993) Ligand-binding properties of the two isoforms of the human insulin receptor. Endocrinology 132: 1132-1138

13. Mosthaf L, Vogt B, Häring HU, Ullrich A (1991) Altered expression of insulin receptor types $A$ and $B$ in the skeletal muscle of non-insulin-dependent diabetes mellitus. Proc Natl Acad Sci USA 88: 4728-4730

14. Mosthaf L, Eriksson J, Häring HU, Groop L, Widén E, Ullrich A (1993) Insulin receptor isotypes expression correlates with risk of non-insulin-dependent diabetes mellitus. Proc Natl Acad Sci USA 90: 2633-2635

15. Norgren S, Zierath J, Galuska D, Wallberg-Henriksson H, Luthman H (1993) Differences in the ratio of RNA encoding two isoforms of the insulin receptor between control and NIDDM patients. Diabetes 42: 675-681

16. Benecke H, Flier JS, Moller DE (1992) Alternatively spliced variants of the human insulin receptor protein. $\mathbf{J}$ Clin Invest 89: 2066-2070

17. Anderson CM, Henry RR, Knudson PE, Olesky JM, Webster NJG (1993) Relative expression of insulin receptor isoforms does not differ in lean, obese, and noninsulin-dependent diabetes mellitus subjects. J Clin Endocrinol Metab 72: 1380-1383

18. Hansen T, Bjorbaek C, Vestergaard H, Gronskov K, Bak JF, Pedersen O (1993) Expression of insulin receptor spliced variants and their functional correlates in muscle from patients with non-insulin-dependent diabetes mellitus. J Clin Endocrinol Metab 77: 1500-1505

19. Sesti G, Marini MA, Tullio AN (1991) Altered expression of the two naturally occurring human insulin receptor variants in isolated adipocytes of non-insulin-dependent diabetes mellitus patients. Biochem Biophys Res Comm 181: $1419-1424$
20. Kellerer M, Sesti G, Seffer E et al. (1993) Altered pattern of insulin receptor isotypes in skeletal muscle membranes of type II (non-insulin-dependent) diabetic subjects. Diabetologia 36: 628-632

21. Scatchard G (1949) The attraction of proteins for small molecules and ions. Ann NY Acad Sci 51: 660-675

22. Harrison LC, Flier J, Itin A, Kahn CR, Roth J (1979) Radioimmunoassay of the insulin receptor: a new probe of receptor structure and function. Science 203: 544-547

23. Roth RA, Beaudoin J (1986) A solid phase competitive radioimmunoassay for the insulin receptor. Anal Biochem 159: $163-168$

24. Pezzino V, Papa V, Trischitta V (1989) Human insulin receptor radioimmunoassay: applicability to insulin-resistant states. Am J Physiol 257: E451-E457

25. McFarland KC, Ramachandran J, Grunfeld C (1989) Peptide-based radioimmunoassay for insulin receptor. Diabetes 38: 987-990

26. Boden G, Jadali F, Tappy L, Fujita-Yamaguchi Y (1991) A radioimmunoassay for human insulin receptor correlation between insulin binding and receptor mass. Horm Metab Res 23: 117-121

27. Sesti G, Tullio AN, Marini MA et al. (1994) Role of the exon 11 of the insulin receptor gene on insulin binding identified by anti-peptide antibodies. Mol Cell Endocrinol 101: 121-127

28. Whittaker J, Okamoto AK, Thys R, Bell GI, Steiner DF, Hofmann CA (1987) High-level expression of human receptor cDNA in mouse NIH 3T3 cells. Proc Natl Acad Sci USA 84: 5237-5241

29. National Diabetes Data Group (1979) Classification and diagnosis of diabetes mellitus and other categories of glucose intolerance. Diabetes 28: 1039-1057

30. Bradford MM (1978) A rapid and sensitive method for the quantitation of microgram quantities of protein utilizing the principle of protein-dye binding. Anal Biochem 72: 248-254

31. Gherzi R, Sesti G, Andraghetti G (1989) An extracellular domain of the insulin receptor $\beta$-subunit with regulatory function on protein-tyrosine kinase. J Biol Chem 264: 8627-8635

32. Ullrich A, Gray A, Tam AW (1986) Insulin-like growth factor I receptor primary structure: comparison with insulin receptor suggests structural determinants that define functional specificity. EMBO J 5: 2503-2512

33. Sesti G, Tullio AN, D'Alfonso R (1994) Tissue-specific expression of two alternatively spliced isoforms of the human insulin receptor protein. Acta Diabetologica 31: 59-65

34. Norgren S, Zierath J, Wedell A, Wallberg-Henriksson H, Luthman H (1994) Regulation of human insulin receptor RNA splicing in vivo. Proc Natl Acad Sci USA 91: 1465 1469

35. Kosaki A, Webster NJG (1993) Effect of dexamethasone on the alternative splicing of the insulin receptor mRNA and insulin action in HepG2 hepatoma cells. J Biol Chem 268: 21990-21996

36. Norgren S, Sheng Li L, Luthman H (1994) Regulation of human insulin receptor RNA splicing in HepG2 cells: effects of glucocorticoid and low glucose concentration. Biochem Biophys Res Comm 199: 277-284

37. Sell SM, Reese D, Ossowski VM (1994) Evidence for insulin regulation of alternative splicing of insulin receptor pre-mRNA. Diabetes 43 [Suppl 1]: 176A (Abstract) 